\title{
Endoscopic resection of a large colonic leiomyosarcoma
}

Leiomyosarcoma of the colon is a rare tumor (330 reported cases [1]) which can mimic an adenocarcinoma [2]. Contrastenhanced computed tomography (CT) is the imaging method of choice in the diagnostic work-up, though magnetic resonance imaging may be useful. Endoscopy and endoscopic ultrasonography (EUS) are also useful for further characterizing the lesion, and are helpful in distinguishing a benign lesion from a malignant one [3]. Positron emission tomography can be used to monitor the response to therapy or detect local recurrence [2]. The management of leiomyosarcomas involving the gastrointestinal tract depends on the confidence in the preoperative diagnosis, and the treatment of choice is radical surgical excision [4]. No data are available on endoscopic treatment in patients who cannot undergo surgery.
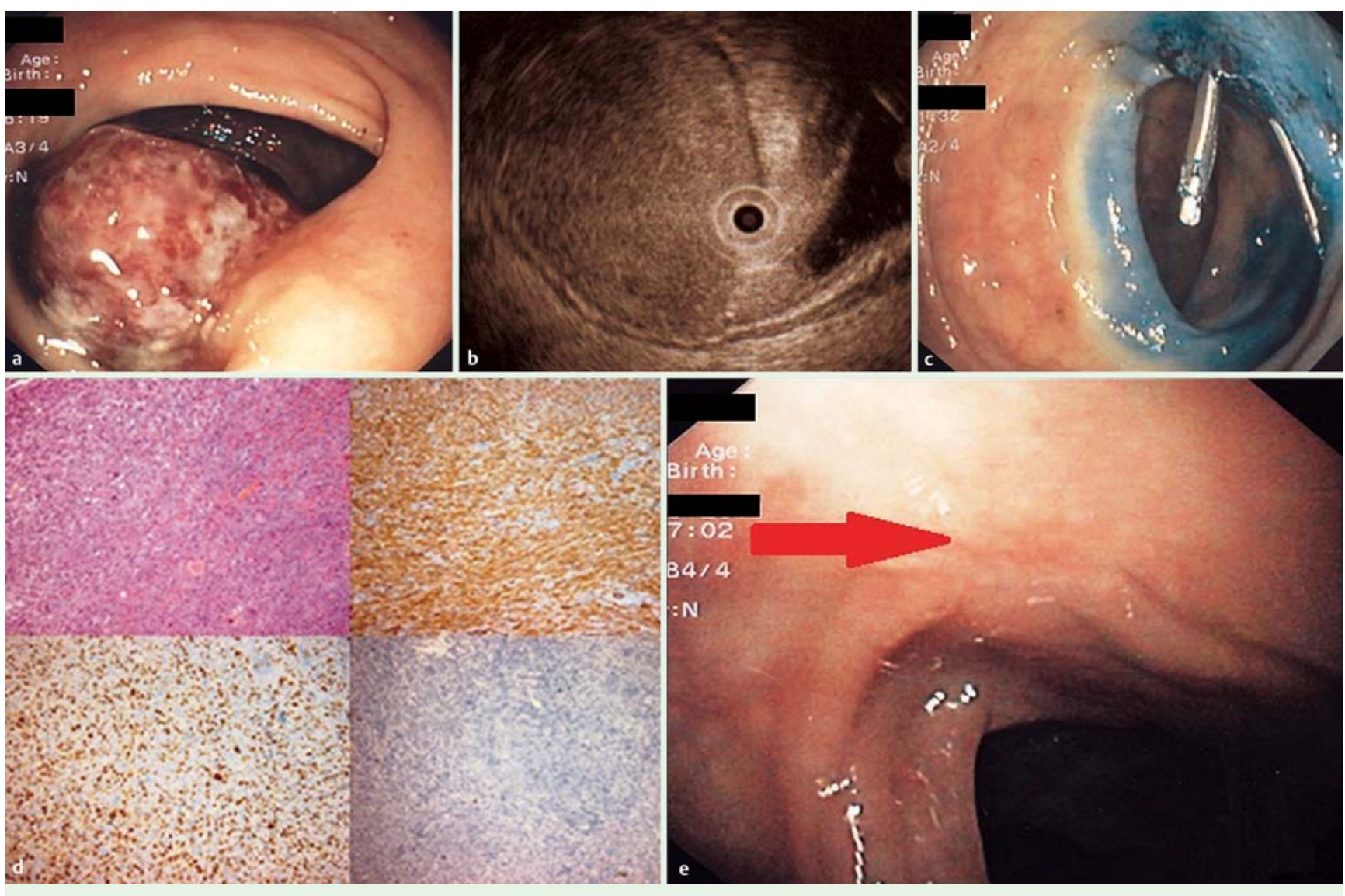

A 64-year-old man affected with hepatitis $C$ virus-related decompensated cirrhosis was admitted to our hospital because of rectal bleeding. At colonoscopy a large sigmoid polyp (diameter $2.5 \mathrm{~cm}$ ) was found ( $\bullet$ Fig. 1 a). At EUS with a $20-\mathrm{mHz}$ miniprobe the polyp was seen as rising from the second and third layers ( $\bullet$ Fig. 1 b). At histopathology the diagnosis was true leiomyosarcoma. CT scan was negative for metastatic lesions. Taking into account the severe liver disease, and in agreement with the surgeon, an endoscopic mucosectomy was performed after injection with saline, epinephrine, and dilute methylene blue into the base, obtaining a complete lift. The polyp was resected en bloc with a snare, using coagulation current followed by Endo Cut current. At the end, clips were placed at the mucosectomy site to prevent delayed bleeding ( $\bullet$ Fig. 1 c). The histopathology of the re- sected specimen confirmed the diagnosis ( $\bullet$ Fig.1d). At 6-month distal endoscopy there was no local recurrence $(\bullet$ Fig. 1 e), and PET scan was negative.

Although surgery is the treatment of choice in operable patients affected with leiomyosarcoma, this report shows that in selected inoperable patients with no metastatic disease, endoscopic excision of leiomyosarcoma can be an effective and safe nonsurgical approach.

\section{Endoscopy_UCTN_Code_TTT_1AQ_2AD}

\section{Competing interests: None}

Fig. 1 a Endoscopic view of the polyp. $\mathbf{b}$ Endoscopic ultrasound image of the polyp base. $\mathbf{c}$ Endoscopic view of the polyp base after removal. $\mathbf{d}$ Final histopathology of the resected specimen. e Endoscopic view of the polyp base at 6-month follow-up (arrow). 
R. Di Mitri ${ }^{1}$, F. Mocciaro ${ }^{1}$, G. Lipani², A. Marino ${ }^{1}$

${ }^{1}$ Gastroenterology and Endoscopy Unit, A.R.N.A.S. Civico-Di Cristina-Benfratelli Hospital, Palermo, Italy

2 Pathology Unit, A.R.N.A.S. Civico-Di Cristina-Benfratelli Hospital, Palermo, Italy

\section{References}

1 Resch T, Oberhuber R, Zitt M et al. Leiomyosarcoma of the colon: unresolved issues of a rare but highly aggressive malignancy. Am Surg 2011; 77: E62 -E64

2 Manouras A, Pappas A, Katergiannakis $V$ et al. Gastrointestinal stromal tumors of the rectum: report of five cases. Acta Gastroenterol Belg 2009; 72: 257-261

3 Boyce GA, Sivak MVJr, Rösch T et al. Evaluation of submucosal upper gastrointestinal tract lesions by endoscopic ultrasound. Gastrointest Endosc 1991; 37: 449-454

4 DeMatteo RP, Lewis JJ, Leung D et al. Two hundred gastrointestinal stromal tumors: recurrence patterns and prognostic factors for survival. Ann Surg 2000; 231: 51-58

\section{Bibliography}

DOI http://dx.doi.org/ 10.1055/s-0032-1309864 Endoscopy 2012; 44: E338-E339 (c) Georg Thieme Verlag KG Stuttgart · New York ISSN 0013-726X

\section{Corresponding author}

\section{R. Di Mitri, MD}

Via Strada Ferrata 44/D 90046, Monreale (PA) Italy

robdimitri68@yahoo.it 